\title{
ALBERGUE DE JORNALEROS AGRÍCOLAS EN MORELOS UN ESPACIO DE INTERCAMBIO Y RECONOCIMIENTO
}

\section{Kim Sánchez Saldaña y Adriana Saldaña Ramírez}

\section{Resumen}

Con base en la trayectoria del Albergue de Jornaleros Agrícolas Migrantes en Atlatlahucan, Morelos, México, en la aplicación de programas sociales y en algunas experiencias de corresponsabilidad de actores involucrados, este artículo discute sobre los límites y alcances que ofrece este tipo de vivienda temporal como espacio para implementar estrategias de promoción social, a la vez que permitir relaciones de intercambio y reconocimiento entre trabajadores, productores y población local. Este albergue está lejos de constituir un caso representativo, sin embargo, se trata de mostrar que las condiciones que han permitido sus modestos pero significativos logros pueden ser recuperadas localmente y sentar precedentes para el diseño de políticas públicas alternativas en lugares análogos.

Palabras clave: jornaleros agrícolas migrantes, vivienda temporal, relaciones de reconocimiento, coaliciones campesinas, albergue.

\begin{abstract}
Shelter for migrant workers in Morelos. A space for exchange and recognition

Based on the trajectory of the Shelter of Migrant Agricultural Laborers in Atlatlahucan, Morelos from 1996 to 2011, in the application of social programs, as well as the experiences of co-responsibility of actors involved, the limits and scope offered by this type of temporary housing are discussed as a space to implement social promotion strategies, and at the same time allowing exchange and recognition relationships between workers, producers and the local population. The shelter is far from constituting a representative case; however, it will try to show that the conditions that have allowed its modest but significant achievements can be recovered locally and set precedents for the design of alternative public policies in similar places.
\end{abstract}

Keywords: migrant farm workers, temporary housing, recognition relationships, peasant coalitions, shelter.

Kim Sánchez Saldaña: Licenciada y maestra en Antropología Social. Doctora en Antropología. Profesora-investigadora del Centro de Investigación en Ciencias Sociales y Estudios Regionales (CICSER) de la Universidad Autónoma del Estado de Morelos (UAEM), México.

ORCID iD: 0000-0002-5722-7324

Email: kim.sanchez@uaem.mx

Adriana Saldaña Ramírez: Licenciada y maestra en Antropología Social. Doctora en Ciencias Agropecuarias y Desarrollo Rural. Profesora-investigadora del CICSER, de la UAEM, México.

ORCID iD: 0000-0002-8858-7728

Email: asaldana@uaem.mx

Recibido: 10 de marzo de 2021.

Aprobado: 4 de junio de 2021. 


\section{Introducción}

En este artículo se reflexiona sobre las oportunidades que pueden encontrarse en espacios públicos destinados a vivienda transitoria de los jornaleros agrícolas migrantes para construir relaciones solidarias de reconocimiento que contrastan con las condiciones de asimetría y exclusión a las que estos trabajadores están sometidos en la sociedad mexicana.

Partimos de experiencias concretas del Albergue de Jornaleros Agrícolas Migrantes de Atlatlahucan, ubicado en el estado de Morelos, en la región central de México, ocurridas entre 2003-2005 y en 2015, que apuntan en esa dirección. Este albergue abrió sus puertas en 1996 para cubrir necesidades básicas de hospedaje de trabajadores estacionales que llegaban cada año de julio a octubre - a la región conocida como Los Altos de Morelos para la cosecha de tomate y otras hortalizas. La construcción y el funcionamiento de dicho albergue público se inscribe en las acciones de promoción social que el gobierno federal, a través del Programa de Atención a Jornaleros Agrícolas (PAJA), tuvo en el estado de Morelos. ${ }^{1}$

La zona agrícola de Los Altos de Morelos fue clasificada por el PAJA como una región de atención jornalera, ${ }^{2}$ en la cual el empleo era generado predominantemente por productores o empresarios agrícolas de pequeña escala, por lo que se los apoyaba con recursos económicos para la atención de los trabajadores que contrataban. En el caso de la vivienda, se aportaba hasta un $80 \%$ para la construcción de infraestructura, mientras que el porcentaje restante debía ser financiado por los propios productores. ${ }^{3}$

El mencionado programa ha sido cuestionado y sus críticos coinciden en que, pese a su prolongada existencia, son magros sus resultados y no logró contrarrestar las condiciones de vulnerabilidad, marginación y ex-

$1 \quad$ El PAJA operó a nivel nacional desde 1990 hasta el 2017, dependiente de la entonces Secretaría de Desarrollo Social (SEDESOL). Fue parte de una política social dirigida a la población jornalera, cuyo objetivo era garantizar el ejercicio efectivo de los derechos sociales, incidiendo en la alimentación, la salud y la educación para reducir sus condiciones de vulnerabilidad, a partir de la vinculación interinstitucional.

2 Como regiones de atención jornalera, el PAJA incluía a las zonas agrícolas de producción de cultivos con uso intensivo de mano de obra, los lugares de concentración y tránsito hacia estas zonas y las localidades de residencia en el caso de los migrantes (SEDESOL, 2010).

3 En las zonas agrícolas y previo dictamen de viabilidad de la propuesta entregada por los solicitantes, se apoyó la construcción, ampliación, rehabilitación y equipamiento de albergues para el alojamiento y la prestación de servicios a la población jornalera agrícola. 
plotación laboral de la población jornalera (Castañeda et al., 2016, p. 79). Se denuncia que las contradicciones entre sus propósitos y su quehacer son reflejo de que el PAJA estaba atrapado en un enfoque asistencialista, pese a la intención de sus promotores y defensores (Castañeda et al., 2016; Rojas, 2014).

Paradójicamente, a partir de que dejó de existir, con el cambio de gobierno federal en 2018, sus censores comenzaron a lamentar su desaparición, pues señalan que, pese a sus defectos y limitaciones, el PAJA tuvo iniciativas afortunadas e innovadoras, siendo, en última instancia, el único apoyo que algunas poblaciones jornaleras recibían en materia de alimentación, salud y vivienda. ${ }^{4}$

Tomando en cuenta este debate, pretendemos reflexionar, desde nuestra condición de observadoras, sobre la trayectoria de un albergue en particular, a lo largo de un amplio trabajo de campo realizado en el período 2003-2005 y en la temporada agrícola 2015.

Cabe advertir que nuestro objetivo nunca fue evaluar el desempeño del PAJA, sino conocer los patrones migratorios y la composición de la población trabajadora en la región alteña de Morelos, como se explica más adelante. Sin embargo, en esta perspectiva longitudinal pudimos constatar aciertos $\mathrm{y}$ desaciertos de esta intervención que ahora interesa revisar y, sobre todo, rescatar los que podrían pensarse como escenarios favorables que son propios del universo social en que operó. Y esto a la luz de una discusión más amplia sobre las condiciones que hacen posible que la población jornalera migrante tenga oportunidad de acceder al ejercicio de sus derechos laborales y humanos, considerando la responsabilidad del Estado pero también la participación de otros actores sociales relevantes.

Para explorar estas propuestas, en primer término, se mencionan los datos empíricos y los referentes teóricos desde donde puede ser retomada la discusión que sugerimos. Seguidamente se hace una breve caracterización del contexto agrícola regional, del perfil de los productores y de la dinámica de los mercados de trabajo en que se insertan los jornaleros migrantes. En tercer lugar, se describen los principales rasgos de la población jornalera y sus estrategias de movilidad, con base en nuestros hallazgos. En cuarto término, se describen las características del Albergue de Atlatlahucan y se reportan algunas de las actividades que tuvieron lugar en él. Con base en estas evidencias, se discute si estas experiencias responden a factores detonantes que favorecen relaciones de reconocimiento entre trabajadores, productores y población local. Finalmente, se formulan algunas conclusiones provisionales que apuntan a subrayar la posibilidad de recuperar estos espacios de vivienda públicos, a partir de la coordinación entre el Estado y otros actores

4 Véase, por ejemplo, la opinión de la especialista Antonieta Barrón, de la Universidad Nacional Autónoma de México (UNAM) (Barrón, 2019). 
sociales que contratan y acompañan a la población jornalera, para generar condiciones básicas para el reconocimiento de sus derechos sociales.

\section{Metodología y referentes teóricos}

Como se ha señalado, retomamos resultados de estudios propios realizados desde 2003 y hasta la actualidad sobre diferentes aspectos de la población jornalera que migra a Morelos procedente de comunidades indígenas de estados vecinos (Sánchez, 2008). ${ }^{5}$ En este marco, la región de Los Altos fue de nuestro interés, ya que es uno de los polos de atracción de población jornalera más importantes en la entidad. En ella se ubica el Albergue de Atlatlahucan, un espacio de pernocta de trabajadores migrantes donde levantamos encuestas durante las temporadas de cosecha 2003, 2004, 2005 y 2015, que nos permitieron conocer varios aspectos de los patrones migratorios de los colectivos que acudían a dicha región, así como registrar las permanencias y cambios de estos flujos a lo largo del tiempo. ${ }^{6}$

La información del perfil de los jornaleros migrantes fue complementada, desde una perspectiva etnográfica, con entrevistas semiestructuradas y en profundidad a trabajadores y familiares acompañantes dispuestos a compartir su experiencia, todo lo cual nos ayudó a comprender sus prácticas de movilidad y estrategias de reproducción expresadas en la vida cotidiana de esta población y su trayectoria. Los datos proporcionados por la población jornalera fueron reforzados a través de la observación participante en el albergue, puntos de contratación y las huertas, así como por entrevistas a promotores, productores y población local.

En Morelos predominan los pequeños productores - ejidatarios, propietarios, medieros y rentistas-, cuyos recursos sociales, técnicos y financieros difieren notoriamente de los de los grandes productores y empresas

5 Estas investigaciones fueron realizadas en el marco del proyecto Agricultura y Migración Laboral en Morelos, de la Universidad Autónoma del Estado de Morelos (UAEM), con la dirección de Kim Sánchez y con la participación de un equipo de investigación, tesistas y estudiantes de la Facultad de Humanidades, en el que se aplicaron encuestas, entrevistas y observación participante a productores, trabajadores, autoridades locales y personal del PAJA (Sánchez, 2008 y 2014; Estrada, 2009; Sánchez, Saldaña y Adame, 2015).

6 En 2003 encuestamos a 50 trabajadores, en 2004 a 162 personas, en 2005 a 158 y en 2015 a 80 personas. En los años 2004 y 2005, la encuesta representó a cerca de la mitad de la población registrada en el albergue. Cabe mencionar que las encuestas en esos dos años se realizaron en dos momentos: al inicio de la temporada (agosto) y al momento de mayor afluencia (octubre), con la intención de captar posibles variaciones de la composición sociodemográfica y condiciones laborales a lo largo de la temporada de cosecha (Sánchez, 2008). También se debe advertir que en nuestro trabajo de campo pudimos detectar que existía un subregistro de la población atendida en el albergue, dado que los promotores de PAJA no actualizaban permanentemente las cédulas de registro de entradas y salidas de los huéspedes, debido a sus múltiples tareas logísticas y de administración, pero también a la dificultad que presenta este mercado laboral por la constante y elevada movilidad de los trabajadores; de hecho, en 2004 la mitad de nuestros encuestados no habían registrado su ingreso al albergue. 
agroindustriales de otras regiones dinámicas del país. ${ }^{7}$ Adicionalmente, la relativa cercanía geográfica de los pueblos de origen de los trabajadores y la menor distancia social relativa respecto a sus empleadores se traducen en peculiares prácticas de movilidad y en el desarrollo de redes sociales e interdependencia con la población local. Lo antes expuesto no significa que se diluya el carácter asimétrico de la relación laboral y de trato discriminatorio por la condición indígena de los jornaleros frente a sus patrones, que se consideran superiores por ser mestizos, pero sí introduce cierta gradación en las percepciones de la población jornalera migrante acerca de su entorno laboral (Piñeiro, 2007) y de reconocimiento por parte de muchos pobladores locales.

Para dar cuenta de estas particularidades que inciden en las relaciones laborales entre jornaleros y productores en Los Altos de Morelos, o entre jornaleros y promotores de políticas sociales, nos fueron sugerentes los planteamientos sobre los campesinos de Fernando Landini $(2012,2013)$ y Eric Wolf (1971).

Para Landini $(2012$, p. 2) es fundamental considerar los factores psicosociales y culturales para analizar las prácticas de intercambio entre sujetos con acceso diferencial a recursos y entender por qué los campesinos aceptan como legítimos los vínculos clientelares con quienes ocupan posiciones de poder. ${ }^{8}$ Por su parte, Eric Wolf (1971) señala que el hogar campesino enfrenta presiones diferentes y diferenciadoras, las que en ocasiones puede sobrellevar por medio de alianzas que se caracterizan por ser bastante flexibles y en las que se procura autonomía funcional para resguardarse individual o comunalmente. Debido a esa peculiaridad, Wolf denomina coaliciones a estas alianzas, entendidas como "una combinación o una alianza especialmente transitoria" entre personas o grupos (1971, p. 107).

Este conocido antropólogo proponía una tipología que clasifica los vínculos formados por individuos o grupos que comparten muchos intereses o unidos por un interés común, con las mismas o diferentes posiciones sociales. En cuanto al número de personas e intereses involucrados, las coaliciones pueden ser poliádicas o diádicas, de entrelazamiento múltiple o simple, dependiendo de si existe uno o más intereses. U tercer criterio considera la simetría o asimetría de las posiciones de sus integrantes y las divide entre horizontales o verticales.

7 Esquemáticamente se podría decir que el "patrón" es un campesino de ingresos medios y el "peón" un campesino pobre con poca tierra o sin ella.

8 Landini (2013, p. 2), al estudiar una localidad campesina de la provincia de Formosa, argumenta que las prácticas clientelares ameritan una perspectiva cultural y psicosocial que dé cuenta de los procesos, vínculos y entramados comunitarios en que se apoyan, entendiendo el sentido en que son percibidos por los propios actores y sin calificarlos de "oportunistas". 
Por otro lado, recuperamos el concepto de reconocimiento, de Axel Honneth, ${ }^{9}$ el cual supone una obligación de reciprocidad, en la que las personas singulares están obligadas para con las otras para poder reconocerse así mismas (Faundes, 2017, p. 306). Desde estas reflexiones, pretendemos revisar un universo social marcado por la interdependencia entre campesinos dedicados a la horticultura comercial y campesinos necesitados de emplearse temporalmente en ella, en torno a lo cual sucede un complejo intercambio de bienes y servicios que rebasa la dimensión estrictamente económica. En este sentido, el reconocimiento como relación jurídica está sustentado en el principio de la igualdad y el derecho de contar con las condiciones sociales necesarias para el despliegue de dicha igualdad, lo cual abre un campo confrontativo y de cooperación para la transferencia progresiva o ampliación de los derechos conquistados a otros miembros de la sociedad. Finalmente, Honneth concluye que tales luchas por el reconocimiento pueden actuar como motores de una sociedad que se fortalece inclusivamente, en oposición a una sociedad en donde prima el prejuicio y que camina hacia su propia descomposición (Honneth, 1997, pp. 144-145, citado por Faundes, 2017, pp. 308-309).

A la luz de estos recursos analíticos, se reflexiona sobre la problemática que deriva de este contexto particular en que se inserta la población jornalera indígena migrante en la región alteña de Morelos.

\section{Los Altos de Morelos y su mercado de trabajo estacional}

Los Altos de Morelos es una región que abarca los municipios de Totolapan, Tlayacapan, Atlatlahucan y Yecapixtla, se ubica al norte de la entidad y colinda con la Ciudad de México y el Estado de México. Se especializa en el cultivo de tomate y otras hortalizas en el ciclo primavera-verano (juliooctubre), con una extensión superior a las 1740 hectáreas sembradas, la mayoría a cielo abierto (94\%). Atlatlahucan destaca en la región con alrededor de la mitad de la superficie sembrada de tomate, representando el $60 \%$ de los ingresos municipales obtenidos en su sector agrícola (SIAP, 2020). La producción de Los Altos ocupa un nicho relevante en el mercado interno por su temporalidad y proximidad a la Central de Abastos de la Ciudad de México (CEDA-CM), el principal mercado mayorista y minorista de la Zona Metropolitana del Valle de México.

El cultivo comercial de tomate se inició en la región a mediados del siglo XX, sustentado por productores de pequeña escala (con entre 1 y 3 hectáreas), quienes transitaron de ser campesinos de subsistencia a horticultores

9 Agradecemos la sugerencia de Andrés Pedreño (2020) de retomar planteamientos del filósofo Axel Honneth enmarcados en su teoría del reconocimiento, para debatir sobre los problemas de violación de derechos humanos y discriminación del jornalero agrícola migrante. 
especializados con experiencia tecnológica y en el mercado, que complementan este cultivo con otros (Guzmán y León, 2008). Se considera que a lo largo de tres o cuatro generaciones los productores de Los Altos han alcanzado una especialización productiva agrícola, sin dejar de ser campesinos, basada en un hábil manejo paralelo de diversos cultivos (comerciales y de autoconsumo), la mano de obra familiar y la contratación de fuerza de trabajo temporal (Guzmán y León, 2008). Las estrategias de reproducción social de este campesinado también incluyen en menor medida ingresos no agrícolas.

La región concentra sus cosechas entre septiembre y octubre, circunstancia que le ha permitido ocupar los primeros lugares en la producción nacional en tales meses, ${ }^{10}$ sin tener que competir con los grandes productores como Sinaloa y Baja California (cultivos de ciclo otoño-invierno), que abastecen a los mercados nacionales e internacionales. En el presente siglo, la superficie sembrada de tomate ha disminuido, sin embargo, la región alteña continúa contribuyendo con el $70 \%$ de la producción estatal de este cultivo.

El productor se encarga directamente de su huerta, con mano de obra familiar y contratación de algunos peones, sobre todo para el corte y el empaque, este último realizado a pie de huerto o en espacios habilitados para ese fin en casa del productor. ${ }^{11}$ Los trabajadores empleados son de 8 a 12 cortadores y de 2 a 6 envasadores. ${ }^{12}$ A partir de julio la demanda de trabajo va en aumento, conforme las plantas se desarrollan (colocación de postes o varas, tendido de guías, podas y deshierbes), y luego se suceden las cosechas, que se prolongan hasta fines de octubre, lo que exige la contratación de cuadrillas eficientes, compuestas mayormente por jornaleros migrantes.

Esta población flotante se concentra en las cabeceras municipales de Atlatlahucan y Totolapan, y en la localidad de Achichipico (municipio de Yecapixtla), que funcionan como centros de contratación de mano de obra, siendo el primero el más importante y con mayor antigüedad (ver Mapa 1). Las contrataciones son directas entre productores y jornaleros, sin intermediarios laborales. Los productores no tienen la capacidad de emplearlos por largos períodos de tiempo, así que el cambio diario de "patrón" es una cons-

10 En la temporada primavera-verano 2018, Morelos fue el segundo productor de tomate en cuanto a superficie sembrada, con alrededor de 2300 hectáreas, solo después de Michoacán con 4300 hectáreas Mientras que en otoño-invierno la producción en Sinaloa fue la más importante, con alrededor de 13.000 hectáreas sembradas, seguida por Baja California y Michoacán (SIAP, 2018).

11 El empaque consiste básicamente en la selección del producto (por tamaño y color) y la preparación de las cajas de madera que tienen diferente precio según la calidad estipulada. En los últimos años surgió la modalidad de venta por tonelada ("al boleo"), promovida por intermediarios comerciales que compran el producto a pie de huerto y lo trasladan en bins, lo que suprime el uso de empacadores.

12 Los empacadores son trabajadores locales y migrantes especializados, que perciben mayor remuneración, reciben mejor trato y con frecuencia se emplean en diferentes regiones tomateras a lo largo del año, aprovechando que algunas cosechas ocurren en diferentes períodos. 
tante para los jornaleros, como también el riesgo de no conseguir empleo uno o más días de la semana. Una minoría trabaja "de planta", lo que en la región quiere decir una semana o más con el mismo productor. Por otro lado, la ausencia de intermediarios ha permitido a los jornaleros negociar mejores condiciones laborales, como un salario superior al que reciben en otros mercados de trabajo rurales del país, una jornada establecida de siete horas y el pago de horas extras cuando esta se extiende. ${ }^{13}$

\section{Mapa 1. Los Altos de Morelos y centros de contratación de jornaleros} agrícolas

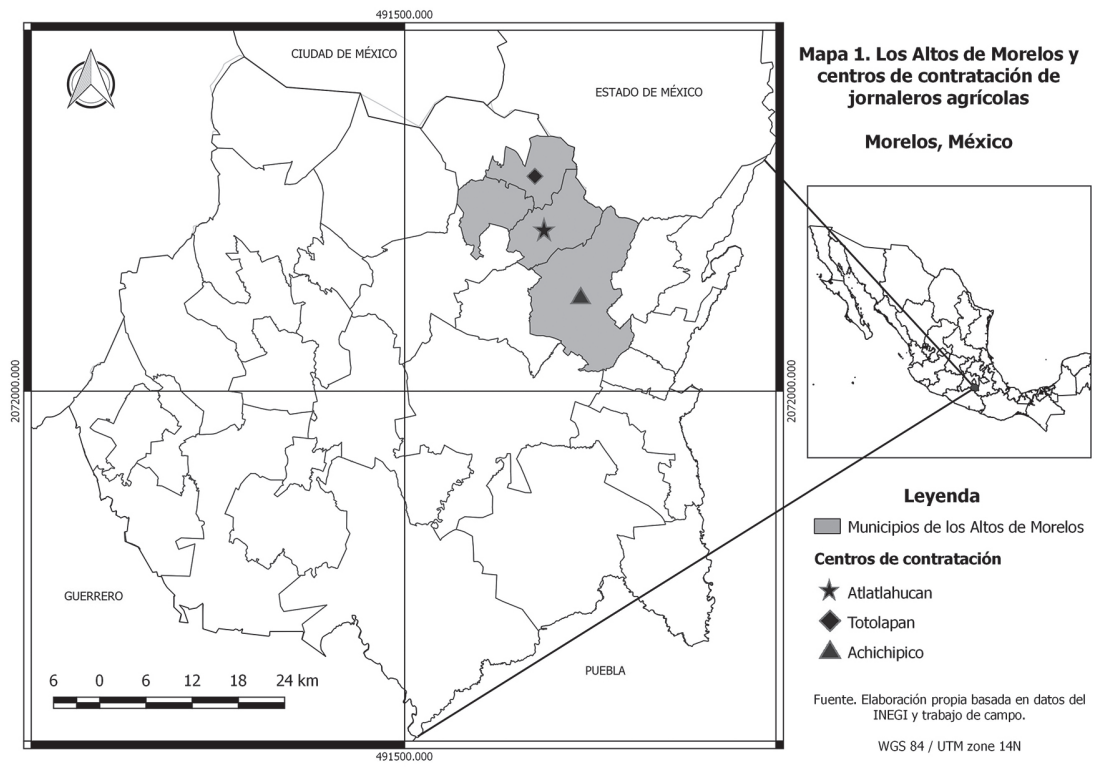

Fuente: Elaboración propia con base en datos de INEGI y trabajo de campo.

Si bien no hay datos estadísticos oficiales del volumen de esta población trabajadora migrante, en 2003 la Coordinación Estatal del PAJA estimaba que a los cuatro municipios que conforman la región habían arribado ese año alrededor de 2000 personas, entre trabajadores y acompañantes (Comunicación personal de promotores del PAJA, 2003). Se trata de un mercado de trabajo migratorio modesto comparado con los grandes polos de atracción del noroeste del país, que emplean decenas de miles de jornaleros. Para los temas que aquí se presentan, la región de Los Altos de Morelos es relevante si se

13 En 2015, el pago por jornada de siete horas era de 120 a 180 pesos (6 a 9 dólares). Si el productor requería que el trabajador permaneciera más tiempo, entonces le pagaba un extra de 35 pesos (1,76 dólares), cuota conocida como "tardeada". 
toma en cuenta que 4 de cada 10 jornaleros agrícolas en México se emplean con pequeños y medianos productores (SEDESOL, 2009). Es decir, si bien las modernas empresas agroindustriales son capaces de movilizar enormes flujos de trabajadores, no puede soslayarse que existen otros esquemas de trabajo que deben ser tomados en cuenta en función de posibles acciones de incidencia social.

\section{Población jornalera, tradiciones migrantes y tendencias ${ }^{14}$}

Cabe mencionar que el campo morelense ha sido históricamente un polo de atracción de migración jornalera de comunidades indígenas de Guerrero y Oaxaca, tanto por la zafra azucarera como por el cultivo comercial de algunas hortalizas en diferentes regiones, en particular para su cosecha manual.

En el caso de Los Altos, los desplazamientos se concentran entre julio y octubre, siendo distinto el flujo migratorio que llega a cada poblado que opera como centro de contratación (Atlatlahucan, Totolapan y Achichipico), resultado de que las redes sociales entre trabajadores y población local marcaron su composición y desarrollo. ${ }^{15}$ Más aún, debido a los factores que favorecen una direccionalidad específica de estos flujos migratorios, se puede encontrar tendencias marcadas en cuanto a su filiación local y lingüística. Además, tales factores propician que en cada lugar exista un número significativo de trabajadores y familias de "tradición", cuya experiencia en Morelos se hereda de padres a hijos por dos o tres generaciones. Sin duda, para los jornaleros migrantes tal experiencia y el capital social acumulado pueden representar ventajas importantes en un mercado laboral caracterizado por la incertidumbre y la inestabilidad, ya sea para conseguir empleo cada temporada para ellos y sus familiares o quienes los acompañen, o para obtener un lugar donde quedarse, acceso a información sobre diferentes aspectos laborales y otros datos que facilitan su estadía.

En efecto, se observa que en Los Altos de Morelos predomina la presencia de comunidades tlapanecas de Guerrero y mixtecas de Oaxaca; en menor medida se encuentran migrantes nahuas y mixtecos también guerrerenses. Una de las consecuencias de este patrón migratorio es que, pese a las condiciones vulnerables de su estadía en Morelos, los vínculos parentales y comu-

14 Este apartado se basa en datos recopilados en nuestras propias investigaciones, dada la carencia de registros oficiales sistemáticos sobre la población trabajadora migrante (Sánchez, 2008 y 2014; Sánchez, Saldaña y Adame, 2015). Los estudios de Elsa Guzmán (2009) y de la misma autora en coautoría con Arturo León López (2008), sobre los campesinos tomateros de Los Altos, han sido claves para entender quiénes son los empleadores y sus estrategias productivas.

15 De hecho, hemos constatado en nuestros estudios que cada una de las regiones agrícolas de Morelos que son polo de atracción de mano de obra migrante representa un nicho específico para diferentes flujos de jornaleros agrícolas que en la temporada de demanda predominan sobre los peones locales y se concentran en unas pocas localidades de destino (Sánchez, 2008). 
nitarios tienen cierta continuidad mientras están ausentes de sus pueblos, lo cual opera como un mecanismo de cohesión intergrupal.

Adicionalmente, se puede mencionar en cuanto al perfil sociodemográfico de los flujos migratorios que aquel que se dirige a Atlatlahucan se caracteriza por ser masculino, compuesto por hombres que suelen viajar en grupos de parientes y paisanos - y en menor medida solos-, con cierta presencia de adolescentes en el mes de julio (vacaciones escolares de verano), mientras que a Totolapan y Achichipico arriban familias completas. En general, el empleo de mano de obra infantil es poco frecuente (Sánchez, 2008).

Una característica importante de estos trabajadores es que son campesinos que en sus pueblos siembran milpa. ${ }^{16}$ La mayoría deja gran parte de las tareas realizadas en su parcela antes del inicio de la temporada de trabajo en Morelos, encargando su vigilancia a otros miembros de su familia o paisanos mientras se encuentran ausentes. La primera pizca de la milpa la llevan a cabo los propios trabajadores cuando retornan a sus pueblos. El hecho de que no cuenten con un empleador fijo ni con empleo todos los días de la temporada en Morelos permite a los trabajadores regresar a sus comunidades de origen en alguna situación especial, debido a su relativa cercanía (alrededor de un día de transporte), lo cual es un rasgo que se refleja en sus estrategias de movilidad. ${ }^{17}$

Los jornaleros migrantes permanecen en Los Altos por períodos variables de uno a tres meses (a veces interrumpidos por aquellos retornos temporales al pueblo). La modalidad migratoria predominante es pendular y solo una minoría participa en circuitos migratorios más amplios en otras regiones tomateras (que se encuentran en los estados de Michoacán, Jalisco y Sinaloa), aprovechando que las temporadas de cosecha son escalonadas.

\section{El Albergue de Atlatlahucan y sus usuarios}

La población jornalera migrante reside temporalmente en Atlatlahucan, Totolapan y Achichipico. ${ }^{18}$ La mayoría ocupa cuartos rentados por los propios trabajadores en poblaciones aledañas a los sitios de trabajo (conocidos como cuarterías) y casas en obra negra que la población local renta para la ocasión, así como viviendas provisionales con materiales frágiles construidas

16 En México, en los pueblos campesinos e indígenas se siembra la milpa, que es un policultivo que tiene como eje el maíz, para autoabastecimiento.

17 El perfil del trabajador que llega a Los Altos contrasta con el de otras regiones en Morelos, donde se extiende entre los migrantes la progresiva pérdida de la agricultura de autoconsumo, lo que los obliga a la venta de su fuerza de trabajo siguiendo las cosechas en diferentes regiones y momentos en el año en todo el país.

18 Es de notar que no existe como tal un centro de contratación en el municipio de Tlayacapan, que también pertenece a Los Altos de Morelos. 
por los propios trabajadores en terrenos prestados o alquilados; unos pocos se instalan con familiares que ya viven asentados en Morelos. La mayor parte de estas viviendas no cuenta con servicios básicos (drenaje, agua, luz, entre otros) o estos son insuficientes. ${ }^{19}$

Excepción de esta precariedad ha sido el Albergue de Jornaleros Agrícolas Migrantes de Atlatlahucan, que comenzó a operar en 1996, con presupuesto federal, estatal y municipal, para dar alojamiento a 240 personas. La cantidad de huéspedes era fácilmente duplicada cada temporada de pizca debido a la alternancia que resultaba de las constantes llegadas y salidas de los jornaleros migrantes, típicas de este escenario laboral, sin que hubiera serios problemas de hacinamiento. ${ }^{20}$ Durante el mes de agosto, por ejemplo, el albergue alojaba a muchos jóvenes que, solos o acompañados por familiares mayores, aprovechan el período vacacional para hacerse de ingresos, y cuando reinicia el ciclo escolar vuelven a sus pueblos. Funcionarios del PAJA calculaban que el Albergue de Atlatlahucan atendía a cerca de la mitad de los trabajadores que llegaban anualmente a esa localidad, estimados en más de un millar.

Considerado un "albergue modelo", fue gestionado por el PAJA de 1996 a 2011, asignando promotores y programas sociales en cada temporada. ${ }^{21}$ Luego estuvo desatendido por un par de años y el gobierno municipal lo reabrió entre 2013 y 2015, con escaso presupuesto y un apoyo mínimo del gobierno federal. ${ }^{22}$ En abril de 2020, en el contexto de la contingencia sanitaria por COVID-19, se consideró como un espacio de emergencia de atención municipal, por lo que los jornaleros migrantes no pudieron usarlo.

19 En general, en México los trabajadores agrícolas migrantes durante su empleo en diferentes localidades de destino pueden ocupar viviendas temporales o transitorias de distinto tipo. Estas pueden ser albergues públicos para trabajadores temporales, campamentos bajo control particular de las empresas agrícolas y proporcionados a los trabajadores como parte de los servicios que otorga el empleador, cuarterías en poblados aledaños a los campos o viviendas provisionales que los trabajadores mismos construyen en terrenos rentados o prestados por pobladores locales, entre las principales modalidades.

20 Cabe destacar que el hacinamiento es uno de los problemas comunes de la habitación jornalera en México, denunciado por diferentes organismos y estudios (Echeverría, Ángeles y MirandaMadrid, 2019; RNJJA, 2019, entre muchos otros).

21 Existe también un albergue para jornaleros en Totolapan, sin embargo, por su ubicación y ausencia de dirección del PAJA tuvo poca aceptación desde que abrió en 2008. En el caso de las familias que arriban a Achichipico (municipio de Yecapixtla), el PAJA construyó un módulo de servicio integral (MOSI), que funcionaba solamente como guardería para los hijos de jornaleros, migrantes temporales y asentados (2004-2005). En 2006 dejó de operar por discrepancias políticas en la administración estatal del PAJA.

22 Según personal del gobierno local, en 2013 se recibió el albergue en condiciones de abandono, pues no se ejecutaba ningún programa. En este período hubo robo de mobiliario. 
Su infraestructura consta de tres módulos de habitaciones con literas, baños y lavaderos, comedor, cocina, áreas comunes y una cancha de básquetbol. Se ubica en las orillas de la localidad y algo distante respecto al punto que funciona como centro de contratación, por lo que los jornaleros debían levantarse de madrugada para llegar a tiempo y conseguir empleo.

Este albergue ha sido utilizado por hombres, en su casi totalidad originarios de comunidades indígenas tlapanecas, mixtecas y nahuas de Guerrero y mixtecas de Oaxaca. ${ }^{23}$ Alrededor de la mitad eran hablantes de mixteco, incluyendo dos o más variantes dialectales (sean de Oaxaca o de Guerrero) ${ }^{24}$ Más de una cuarta parte eran hablantes de lengua indígena me'phaa o tlapaneca ${ }^{25}$ casi todos bilingües. La mayoría eran jóvenes (29 años y menos), con algún grado de escolaridad, predominando la primaria completa y, entre los adolescentes, la secundaria.

En este microcosmos pluriétnico, dadas las prácticas de movilidad ya señaladas, se producía en el albergue un agrupamiento natural por módulo, basado en paisanaje e identidad lingüística, lo cual añadía sentimientos de familiaridad y confianza entre huéspedes. Incluso los mismos promotores al arribar un nuevo trabajador lo acomodaban de acuerdo con su filiación étnica y parroquial, a menos que este se opusiera o hubiera problemas de espacio.

De 1996 a 2011 el PAJA fue responsable de dar comidas y cenas por una módica cantidad que se reinvertía para la compra de despensa. El gobierno municipal apoyaba con personal (cocinera y velador) y servicios de agua y luz. Los usuarios aportaban una tarifa semanal asequible por el alojamiento ${ }^{26}$ y tenían el compromiso de colaborar en el mantenimiento de las áreas comunes, cuestión que no era ajena a las tradiciones de trabajo comunitario voluntario de sus pueblos con fines de utilidad social. El propósito era hacer un proyecto autofinanciable con respaldo institucional para garantizar acciones de promoción social. En este sentido, mientras el PAJA administró este espacio se impartieron cursos de capacitación con apoyo de diversos organismos públicos estatales y se otorgó a los jornaleros una beca por su asistencia, por ejemplo, a talleres de carpintería y electricidad.

23 Los datos se basan en cuatro encuestas que realizamos en 2003, 2004, 2005 y 2015. Al momento de la aplicación, los encuestados representaban el $25 \%$ de la población trabajadora en el albergue en 2003, un 50\% de la alojada en 2004 y $60 \%$ de la correspondiente a 2005 (Sánchez, 2008). Posteriormente, en 2015, la encuesta se aplicó a 32\% de la población atendida hasta el momento en que fue realizada, que ascendía a 247 trabajadores (Sánchez, Saldaña y Adame, 2015).

24 Los asentamientos históricos se encuentran en los estados de Oaxaca, Puebla y Guerrero. En el Censo de Población y Vivienda del Instituto Nacional de Estadística y Geografía (INEGI) 2010 se registraron 496.038 hablantes de alguna variedad de mixteco.

25 El idioma tlapaneco o me'phaa se habla en el centro y sur del estado de Guerrero, en México. Su población lingüística rebasa los cien mil hablantes (INEGI, 2010).

26 El costo equivalía a menos de un $20 \%$ de lo que las cuarterías en la región cobraban a la semana. 
También los Servicios de Salud de Morelos realizaron ferias de salud, actividad mantenida mientras estuvo abierto el albergue, pues no dependía de las gestiones de PAJA. ${ }^{27}$

Adicionalmente, al inicio de septiembre, se realizaba un festival de bienvenida a los trabajadores migrantes (aunque el lugar estuviera funcionando desde agosto), para agradecer formalmente su apoyo a la economía regional. Estos eventos tenían el sello característico de actos políticos con varias autoridades estatales y locales, bandas de música y demás parafernalia, y concluía con una modesta cena ofrecida a los trabajadores. Posiblemente para estos solo representaba un momento de esparcimiento o bien de la oportunidad de recibir algún apoyo. En el marco del festival de 2005 se hizo entrega de los premios de un torneo de básquetbol, pues con antelación se habían formado equipos que competían por las preseas y los premiados recibieron ropa deportiva, balones y trofeos. No se pierde de vista que estos eventos eran en sí mismos clientelares.

También vale comentar que en las temporadas agrícolas de 2004 y 2005 (con el aval del PAJA), la UAEM, por iniciativa del proyecto Agricultura y Migración Laboral en Morelos, realizó algunas actividades culturales, por ejemplo, una exposición fotográfica con apoyo del Centro Regional Morelos del Instituto Nacional de Antropología e Historia (INAH) ${ }^{28}$ Aunque eran acciones aisladas, estos eventos tuvieron buena aceptación entre los huéspedes del albergue y, en última instancia, mostraron que era factible que colaborasen instituciones como la UAEM. ${ }^{29}$

Finalmente, vale mencionar que algunos jornaleros migrantes de Los Altos recibieron apoyo de la Secretaría de Trabajo y Previsión Social (STPS) para gastos de traslado desde sus comunidades hacia Morelos, a través del Subprograma de Movilidad Laboral Interna (SUMLI).

Es evidente que el desmantelamiento progresivo y la posterior desaparición del PAJA en 2017 significaron para el Albergue de Atlatlahucan la reducción de la atención a la población jornalera, que en otros años había ofrecido. A pesar de ello, la autoridad municipal, con su limitado presupuesto, lo mantuvo durante algunas temporadas agrícolas para la función elemental del

27 Esta es una actividad programada a cargo de la dependencia estatal de salud para atención básica de población migrante en albergues. Su organización incluye desde la desinfección del albergue antes de su apertura hasta la programación de acciones de acuerdo con características de cada población (si son hombres o familias), etcétera.

28 La exposición "Gente de Campo y Gente de Jale" consistió en imágenes de los trabajadores agrícolas en diferentes cultivos y regiones de Morelos, de autoría de integrantes del equipo de investigación, del PAJA y del INAH. Posteriormente, dicha exposición se presentó en Cuernavaca en el Museo Regional Cuauhnáhuac y La Casa de Ciencia, de la UAEM. Otra actividad bien recibida fue la que se llamó Ciclo de Cine de Humanidades, y algunos de los jornaleros con mayor confianza esperaban para ver qué película se llevaba semanalmente.

29 En la ocasión, ayudaron a generar un clima favorable y respetuoso para la presencia de estudiantes "entrometidos" que hacían entrevistas, encuestas y tomaban fotos. 
albergue, esto es, la pernocta de los trabajadores en condiciones de higiene y seguridad, pero sin los otros servicios descritos.

\section{¿Es posible un entorno saludable en el Albergue de Atlatlahucan?}

En primer lugar, interesa retomar aspectos centrales de esta experiencia y del contexto social en que tuvo lugar para iniciar la discusión sobre las posibilidades y limitaciones de estos espacios para generar un entorno saludable que dignifique a los trabajadores. Hemos tratado de brindar elementos suficientes para que se aprecie en qué condiciones operó el Albergue de Atlatlahucan entre 1996 y 2011 con la gestión del PAJA y hasta qué punto fue un espacio que los trabajadores adaptaron a sus necesidades y prácticas de movilidad en este contexto migratorio.

La habitabilidad del albergue y una alimentación aceptable a módicos precios, así como el acceso a recursos educativos (en especial para los jóvenes), las actividades recreativas y un sentimiento de respeto, fueron factores decisivos para entender por qué los jornaleros apreciaban el lugar, cumplían con las tareas de limpieza que eran familiares a sus tradiciones de trabajo voluntario y regresaban al siguiente año, aunque estuviera alejado del lugar donde se realizaban las contrataciones. ${ }^{30}$

Esta serie de cualidades contrasta con las deficientes condiciones de las viviendas temporales para jornaleros agrícolas que numerosos estudios reportan en diferentes regiones del país, las cuales no solamente afectan la salud por ser insalubres, sino que directamente atentan contra las normas mínimas de convivencia (Echeverría, Ángeles y Miranda-Madrid, 2019, p. 350).

Recientemente, la situación de emergencia sanitaria por COVID-19 ha puesto en evidencia que la precariedad de las condiciones de vivienda es uno de los principales riesgos de propagación de enfermedades entre trabajadores agrícolas, debido al hacinamiento y la insuficiencia de agua para el aseo personal y de la ropa, entre otros problemas de salud pública. ${ }^{31}$ Estas carencias ya habían sido denunciadas antes y convierten a esos lugares de pernocta en "campos de enfermedades" (Ángeles, 2015), mostrando que las grandes empresas no garantizan — aunque tengan más recursos - condiciones ade-

30 Trabajadores entrevistados que residían en cuarterías argumentaban que la lejanía del albergue era una razón para no usarlo. La distancia no es un detalle menor, pues quienes vivían en él debían sacrificar de 20 a 30 minutos de descanso para no perder las oportunidades de conseguir empleo cada día.

31 Sobre el caso español, Andrés Pedreño señala: "En definitiva, lo que la crisis sanitaria una vez y otra pone de manifiesto es que allí donde se concentran poblaciones socialmente vulnerables desde el punto de vista de la precariedad laboral (jornaleros), residencial (chabolismo) o jurídica (inmigrantes irregulares) devienen territorios especialmente propensos al riesgo de contagio. La condición móvil de los jornaleros que van siguiendo las cosechas entre los diferentes territorios eleva la vulnerabilidad de estos trabajadores al riesgo de contagio" (Pedreño, 2020, p. 35). 
cuadas en sus campamentos para los jornaleros, ${ }^{32}$ siendo indispensable la vigilancia y control por parte de la STPS y la Secretaría de Salud (SSA). Para algunos, el interés del sector agroexportador en cumplir con estándares internacionales en la materia daría la oportunidad de avanzar en esa dirección. ${ }^{33}$ Por otro lado, en el caso de albergues públicos o administrados por asociaciones de pequeños productores, organizaciones de la sociedad civil vinculadas con esta problemática ${ }^{34}$ plantean que son también necesarias instancias de coordinación con la STPS y la SSA (federales y estatales) que aseguren que las viviendas jornaleras cumplan con condiciones saludables y, en caso de emergencias sanitarias, pongan en marcha protocolos adecuados a las características de su uso. ${ }^{35}$ Donde la población jornalera incluye a familiares acompañantes y niños, se deduce que los campamentos y albergues deben contemplar necesidades específicas. ${ }^{36}$

Dotar de vivienda digna a los jornaleros, no solo alude a la calidad de la infraestructura, sino también debe ofrecer condiciones de seguridad y privacidad. Pero en el caso de campamentos dentro de la propiedad de los productores, frecuentemente estos funcionan bajo el principio de "encierro", donde los trabajadores son confinados para realizar su trabajo (Echeverría, Ángeles y Miranda-Madrid, 2019). ${ }^{37}$

Desde 2011, la SSA emite una certificación de Albergue Saludable, que ha pretendido estimular a los productores a dotar de infraestructura apro-

32 Entre otros, los estudios de Ángeles Balcázar (2015), Echeverría, Ángeles y Miranda-Madrid (2019) y RNJJA (2019).

33 Al parecer, después de los conflictos laborales de 2015, cuando las empresas agrícolas en Baja California fueron cuestionadas por violación de derechos laborales, la empresa transnacional Driscoll's ha reforzado su cuidado de normas laborales internacionales y mantenido una fuerte campaña para mejorar su imagen. En la actual situación de pandemia ha realizado varias iniciativas para mostrar lo que denominan "responsabilidad corporativa" (Driscoll's, s. f.).

34 Destacan la Red Nacional de Jornaleras y Jornaleros Agrícolas y el Centro de Derechos Humanos de la Montaña de Guerrero, Tlachinollan.

35 En ese sentido se puede mencionar que, en marzo de 2020, la STPS y la SSA publicaron una Guía de acción para los centros de trabajo agrícolas ante el COVID-19, en la que se informaba de estrategias generales de control, para prevenir y evitar la propagación del coronavirus COVID-19 en los centros de trabajo (STPS y SSA, 2020). Varias de las medidas previstas en esta guía, sin embargo, estaban pensadas en función de grandes empresas. En Morelos pudimos constatar que en albergues públicos o administrados por asociaciones de pequeños productores no conocían o no usaron la guía.

36 La Ley Federal del Trabajo (LFT), Capítulo III (Trabajadores de Campo), Artículo 283, en obligaciones espaciales que deben cumplir con los jornaleros, incluye en su acápite XIII "Brindar servicios de guardería a los hijos de los trabajadores (LFT, 2014, 64-66)" (citada en Castañeda et al., 2016, p. 316).

37 De igual manera a lo que reporta Janet McLaughlin (2009, p. 340) sobre el caso de los trabajadores agrícolas temporales en Canadá, las restricciones a la libertad en el ambiente de la vivienda generan un sentimiento de aislamiento y confinamiento entre los trabajadores y afectan su salud emocional. Lo cierto es que los jornaleros, aquí y allá, toleran todas las carencias y los problemas de las viviendas, pues asumen que es parte del costo de tener acceso al empleo y cumplir sus proyectos laborales de supervivencia (Echeverría, Ángeles y Miranda-Madrid, 2019). 
piada, así como facilitar el acceso a servicios de salud. Sin embargo, este recurso es insuficiente, pues, al igual que otras certificaciones, ha sido usado más bien para aumentar la competitividad de las empresas en el mercado internacional o mejorar su imagen, antes que para procurar el bienestar de la población trabajadora (Rojas, 2012, pp. 52-53; citado por Castañeda et al., 2016, p. 59). ${ }^{38}$

La problemática hasta aquí planteada tiene la intención de resaltar la enorme relevancia de la vivienda en la salud de la población jornalera en contextos migratorios. El Plan Integral para la Población Migrante de la SSA ${ }^{39}$ ofrece un marco jurídico general que debería traducirse en normas y mecanismos aplicables a las condiciones particulares y necesidades específicas de la población jornalera agrícola, sin embargo, dicho plan está centrado en la figura del migrante internacional y, por ende, en el refugio temporal para migrantes y en las unidades de atención a migrantes.

Con el fin de alinear sus objetivos a la población móvil de jornaleros agrícolas, sería pertinente entonces reiterar el reclamo de las organizaciones de la sociedad civil respecto a que es necesario que exista una coordinación efectiva entre la STPS y la SSA para realizar inspecciones regulares sobre la infraestructura y el funcionamiento de albergues, campamentos y otras viviendas transitorias, para asegurar que se cree un entorno saludable, incluyendo los espacios que proporcionan servicios en los albergues como las guarderías y centros educativos (RNJJA, 2019). Pero, también, las experiencias del Albergue de Atlatlahucan muestran que la participación directa y organizada de los usuarios en la gestión de estos recursos es factible y pueden sostenerse acciones conjuntas para alcanzar objetivos comunes que beneficien a trabajadores y administradores.

\section{De relaciones clientelares a coaliciones}

Un segundo tema de reflexión que interesa abrir a la discusión se relaciona con la posibilidad de que los jornaleros agrícolas migrantes encuentren espacios de reconocimiento que contrarresten la lógica del desprecio que naturaliza su exclusión social (Honneth, 2019, citado por Pedreño, 2020, p. 12).

Partimos de entender desde una perspectiva cultural que, ante las accio-

38 La validación de Albergue Saludable, sea este público o privado, tiene una vigencia de dos años, la cual puede ser utilizada por los productores para etiquetar sus productos y con ello acceder a otras certificaciones internacionales. Hasta 2016 se habían validado 38 albergues en 9 entidades del país, de los cuales solo 2 estaban en Morelos: uno pertenece a una agroexportadora de capital extranjero, el otro es administrado por un ingenio azucarero privatizado (Castañeda et al., 2016, p. 59).

39 De acuerdo con el Plan Integral para la Población Migrante de la SSA, de 2019: "Además de ser una cuestión de equidad y respeto a los derechos humanos, es también una cuestión de solidaridad humana y de justicia social para con los más desfavorecidos a causa de los procesos de violencia generalizada, desigualdad social y vulnerabilidad económica." (SSA, 2019, p. 17). 
nes asistencialistas promovidas por el PAJA, los jornaleros no eran "clientes" pasivos, ni receptores de caridad, sino que los recursos (en dinero o especie) eran recibidos y aceptados como parte de las relaciones de reciprocidad, ${ }^{40}$ propias de los entornos campesinos donde se espera que el político local o el productor acaudalado sea generoso con quien tiene menos (Landini, 2013).

Lo que aquí se quiere notar es que esas prácticas asistencialistas típicas del PAJA eran percibidas por los trabajadores como un medio legítimo de satisfacer sus necesidades y como un deber moral de los actores con mayor poder económico. Es decir, compartimos la hipótesis de Landini (2013), quien sostiene que se deben tomar en cuenta los valores y las prácticas culturales tradicionales de las sociedades campesinas para comprender el sentido que le atribuyen los "clientes". Esta advertencia analítica es crucial si se pretende formular "políticas públicas transformadoras que escapen a las formas clientelares que tienden a capturarlas" (Landini, 2014, p. 3).

Entonces, si bien la intervención del PAJA en el Albergue de Atlatlahucan promovía esquemas que reproducían el poder de los mediadores que controlaban recursos públicos, al mismo tiempo también es cierto que generaban relaciones y prácticas percibidas por los trabajadores como un intercambio respetuoso de reconocimiento con los productores y las autoridades locales, lo cual no era mérito del PAJA, sino de la presencia de condiciones que hacían posible potenciar la cosmovisión campesina y la cultura laboral construida históricamente en la región. Siguiendo la propuesta de Honneth, es posible la existencia de relaciones solidarias de reconocimiento enmarcadas en la lucha contra la asimetría, el menosprecio, la opresión o la exclusión que subyacen en la sociedad (Faundes, 2017, p. 315).

Pensando en ello, interesa destacar que la región de estudio ofrece un escenario de relaciones económicas e interétnicas de interdependencia entre la agricultura comercial y la agricultura de subsistencia, entre mestizos e indígenas, entre "patrones" y trabajadores estacionales, donde la distancia social y cultural entre unos y otros es menos asimétrica que en otros mercados laborales del noroeste del país (dominados por la agroindustria de grandes capitales), lo cual representa condiciones propicias para concebir relaciones de reciprocidad y solidaridad. Insistimos en que la particularidad de este universo social no es extraordinaria, ya que existen otras regiones en México donde predominan las empresas familiares y los productores en pequeña escala, en algunos casos también organizados en asociaciones campesinas.

40 Para la antropología económica, la reciprocidad no solamente incluye el intercambio entre iguales (por ejemplo, el intercambio de regalos entre socios comerciales), sino también el intercambio entre desiguales, como las relaciones de patronazgo o trasferencias agonísticas, como en el caso de las instituciones de la economía de prestigio. En todos los casos, "[...] la reciprocidad alude a dos fenómenos, a menudo relacionados, a saber, a la circulación diferida de bienes y a un constructo ideológico que afirma la obligación de devolver de forma equilibrada" (Molina y Valenzuela, 2002, p. 140). 
Ahora bien, las dificultades para operar y mantener abierto el Albergue de Atlatlahucan también alertan de lo decisiva que es la voluntad del gobierno para este tipo de proyectos, respaldando y movilizando recursos financieros e institucionales para asegurar la cobertura de los servicios brindados, facilita dispositivos de colaboración, legitimar la construcción de alianzas y crear mejores condiciones para las relaciones sociales de intercambio entre los actores involucrados.

De acuerdo con los criterios propuestos por Wolf (1971, p. 107) en relación con las coaliciones o alianzas flexibles que protagonizan los campesinos, el Albergue de Atlatlahucan podría considerarse un espacio propicio para coaliciones poliádicas de entrelazamiento múltiple, tanto horizontales como verticales. La existencia de intereses compartidos entre actores primarios, sociedad civil y organismos públicos favorece y crea sinergias positivas que podrían promover puentes de comunicación y relaciones recíprocas de reconocimiento, como se logró en otros momentos.

\section{Conclusiones preliminares}

En este artículo se reflexiona sobre la trayectoria del Albergue de Atlatlahucan, uno de los espacios públicos de pernocta para trabajadores agrícolas migrantes en México, construido para atender a los jornaleros migrantes indígenas en Los Altos de Morelos. Al igual que albergues análogos en otras zonas de destino, estas viviendas temporales fueron edificadas y gestionadas como módulos de servicios integrales por el PAJA con un impacto relativo, sin que se hayan logrado contrarrestar las condiciones de vulnerabilidad, pobreza y explotación laboral de la población jornalera.

No obstante, en este espacio se reunieron las condiciones propicias para crear un clima de respeto y reconocimiento de los derechos sociales de los trabajadores. Sostenemos que su gestión permitió vínculos de intercambio entre grupos de trabajadores que compartían intereses y representantes del Estado, que también mediaban la relación con otros actores sociales, en lo que Wolf ha denominado coaliciones poliádicas de entrelazamiento múltiple horizontales y verticales. Las condiciones que permitieron estas prácticas y relaciones resultan de la interdependencia económica entre las comunidades mestizas anfitrionas en Morelos y las comunidades indígenas de origen de los trabajadores, así como de su menor distancia social y cultural respecto a otras regiones agrícolas. No menos importante fue la presencia de políticas públicas orientadas a satisfacer las demandas de esta población trabajadora.

El albergue, gestionado por el PAJA de 1996 a 2011, fue considerado un “albergue modelo" en su tipo. Sin embargo, la desaparición del PAJA mermó la atención que se brindaba a la población jornalera agrícola, dificultando el reconocimiento de su participación en una de las actividades económicas más importantes de la región. Recuperar este espacio y las relaciones entre 
actores sociales que lo sostenían mejoraría las condiciones de vida de los jornaleros migrantes durante la temporada de trabajo y contribuiría al respeto de sus derechos sociales, a la vez que favorecería a las comunidades anfitrionas y la actividad productiva regional.

\section{Referencias bibliográficas}

Ángeles, A. C. (2015). Jornaleros agrícolas migrantes guerrerenses, de los campos de la pobreza a los campos de las enfermedades. Revista electrónica Medicina, Salud y Sociedad, 5(3), pp. 232-250.

Barrón, A. (2019). ¿Y los jornaleros? La Jornada en el Campo, 142, 20 de julio, p. 19.

Castañeda, N.; S. Cruickshank; L. Guercke y M. Verduzco (2016). Diagnóstico sobre la situación de las politicas públicas y atención a personas jornaleras agrícolas migrantes en México. Ciudad de México: Centro de Estudios en Cooperación Internacional y Gestión Pública (CECIG).

Driscolls (s. f.). Sitio web oficial. s. 1.: Driscolls. Disponible en: $<$ https://www. driscolls.com> [acceso 15/01/2021].

Echeverría, M. R.; A. C. Ángeles y A. Miranda-Madrid (2019). Resquicios de vida: habitáculos humanos para los jornaleros agrícolas migrantes en México. Textual, 74, pp. 311-351.

Echeverría, M. R.; L. A. Ávila y A. Miranda-Madrid (2014). Espacios de vida y subjetividades de los jornaleros agrícolas: reglamentaciones morales en sociedades agroempresariales contemporáneas. Agricultura, Sociedad y Desarrollo, 11(4), pp. 517-537.

Estrada, Q. (2009). Migración y empleo en el sureste del Estado de México. En: P. Castro (2009). Dilemas de la migración en la sociedad posindustrial. Ciudad de México: Porrúa /UAM, pp. 113-136.

Faundes, J. (2017). Honneth y la demanda por el reconocimiento intercultural de los pueblos indígenas. Perfiles Latinoamericanos, 25(49), pp. 303-323.

Gómez, D. L. (2020). Contribución para el estado del arte sobre las condiciones de vida de los trabajadores agrícolas en los albergues para jornaleros migrantes en el Estado de Morelos. Memoria de Trabajo, Licenciatura en Antropología Social. Morelos: Universidad Autónoma del Estado de Morelos (UAEM). 
Guzmán, E. (2009). Los productores campesinos de Morelos. Sobre estrategias y mercados. En: K. Sánchez y A. Saldaña (coords.). Buscando la vida. Ciudad de México: Plaza y Valdés, pp. 19-60.

Guzmán, E. y A. León López (2008). Campesinos jitomateros. Especialización diversificada en Los Altos de Morelos. Ciudad de México: Plaza y Valdés.

Instituto Nacional de Estadística y Geografía (INEGI) (2010). Censo de Población y Vivienda. Ciudad de México: INEGI. Disponible en: $<$ http://atlas. inpi.gob.mx $>$ [acceso 01/12/2020].

Landini, F. (2012). Prácticas clientelares y control político en la experiencia campesina de Argentina. Perfiles Latinoamericanos, 40, pp. 205-226.

Landini, F. (2013). Asistencialismo y búsqueda de ayudas como estrategia de supervivencia en contextos campesinos clientelares. Polis. Revista de la Universidad Bolivariana, 12(34), pp.1-12.

McLaughlin, J. (2009). Trouble in our Fields: Health and Human Rights among Mexican and Caribbean Migrant Farm Workers in Canada. Tesis de Doctorado en Filosofía. Toronto: Toronto University.

Molina, J. L. y H. Valenzuela (2007). Invitación a la antropología económica. Barcelona: Bellaterra.

Pedreño, A. (2020). En los márgenes de las cadenas globales agrícolas. La cuestión jornalera en la crisis sanitaria. Trabajo agrario y ruralidades en transformación, 1, pp. 24-40.

Piñeiro, D. (2007). El trabajo precario en el campo uruguayo. Montevideo: Universidad de la República.

Red Nacional de Jornaleros y Jornaleras Agrícolas (RNJJA) (2019). Violación de derechos de las y los jornaleros agrícolas en México. Primer informe. Ciudad de México: RNJJA.

Rojas, T. (2014). Exclusión y política social para la atención de los jornaleros agrícolas. México: Universidad Pedagógica Nacional.

Sánchez, K. (2008). El Albergue de Atlatlahucan, Morelos. Perfiles y trayectorias de los jornaleros migrantes. En: P. Castro. Dilemas de la migración en la sociedad postindustrial. Ciudad de México: Miguel Ángel Porrúa, pp. 39-64.

Sánchez, K. (2014). Prácticas y estrategias identitarias de los me’phaa en Morelos. En L. González y P. Moctezuma. Estudios de comunidad e identidad en espacios multiculturales. Ciudad de México: Juan Pablos Editor/UAEM, 
pp. 121-145.

Sánchez, K. y A. Saldaña (2018). Morelos como destino y origen de trabajadores agrícolas migrantes (2010-2014). Cuernavaca: UAEM.

Sánchez, K.; A. Saldaña y J. M. Adame (2015). El Albergue de Jornaleros Agrícolas Migrantes. Atlatlahucan, Morelos, 2015. Informe Técnico de Investigación. Cuernavaca: UAEM.

Secretaría del Trabajo y Previsión Social (STPS) y Secretaría de Salud (SSA) (2020). Guía de acción para los centros de trabajo agrícolas ante el COVID-19 [en línea]. Ciudad de México: STPS y SSA. Disponible en: https:// www.gob.mx/cms/uploads/attachment/file/546755/Guia_de_accion_para Centros_de_Trabajo_Agri_colas_COVID-19_09042020_1_.pdf [acceso $1 / 12 / 2020$ 2020].

Secretaría de Desarrollo Social (SEDESOL) (2009). Encuesta Nacional de Jornaleros. Módulo de consulta de resultados [en línea]. Ciudad de México: SEDESOL. Disponible en: < http://www.cipet.gob.mx/jornaleros/> [acceso 15 de junio de 2019].

Secretaría de Desarrollo Social (SEDESOL) (2010). Diario Oficial de la Federación. Quinta Sección - Vespertina, 31 de diciembre.

Secretaría de Salud (SSA) (2019). Plan Integral para la Población Migrante. Ciudad de México: SSA.

Servicio de Información Agroalimentaria y Pesquera (SIAP) (2018). Anuario estadístico de la producción agrícola. Ciudad de México: Gobierno de México. Disponible en: <https://nube.siap.gob.mx/cierreagricola/> [acceso 08/01/2021].

Servicio de Información Agroalimentaria y Pesquera (SIAP) (2020). Anuario estadístico de la producción agrícola. Ciudad de México: Gobierno de México. Disponible en: <https://nube.siap.gob.mx/cierreagricola/> [acceso 08/01/2021].

Wolf, E. (1971). Los campesinos. Barcelona: Editorial Labor.

\section{Contribución de autoría}

Este trabajo fue realizado en partes iguales por Kim Sánchez Saldaña y Adriana Saldaña Ramírez. 